\title{
Assessment of Degree of Fibrosis in Chronic Hepatitis C Virus Patients Treated with Direct Acting Antiviral Agents
}

Fathy Ghamry Abd-Elrazik ${ }^{1}$, Magdy Abd-Elkarim Aldahshan', Arafat Abd-Elazim Kasim ${ }^{1}$, Haitham

Ahmed Ali Gabr ${ }^{2}$, Mohamed Nasr Mohamed ${ }^{1}$

${ }^{1}$ Department of Internal Medicine, Faculty of Medicine - Al-Azhar University

${ }^{2}$ Researcher of Internal Medicine, National research center - Cairo

Corresponding author: Mohamed Nasr Mohamed, Mobile: 01270949812;

Email: dr.m.nasr88@gmail.com

\begin{abstract} (sustained virological response, SVR 12 and SVR 24). Institute in Cairo divided into three groups. virological response.

\section{INTRODUCTION}

The liver is a basic organ for numerous physiological procedures which incorporates supplement digestion, blood volume guideline, resistant framework backing, lipid and cholesterol homeostasis, and the breakdown of mixes, including numerous present medications ${ }^{(\mathbf{1})}$.
\end{abstract}

Background: Weighing in at around 3 pounds, the liver is the body's second largest organ; only the skin is larger and heavier. The liver performs many essential functions related to digestion, metabolism, immunity, and the storage of nutrients within the body. These functions make the liver a vital organ without which the tissues of the body would quickly die from lack of energy and nutrients. Fortunately, the liver has an incredible capacity for regeneration of dead or damaged tissues; it can grow as quickly as a cancerous tumor to restore its normal size and function.

Objective: to evaluate the levels of fibrosis regression by ARFI in the patients with successful eradication of chronic hepatitis $\mathrm{C}$ virus after 12 weeks and 24 weeks after completion of treatment with direct acting antiviral drugs

Patients and Methods: This prospective and observational cohort study was conducted during the period between June 2016 and February 2019 in total of 60 individuals at Al-Azhar (Al-Hussein) Hospital and National Search

Results: Results show that the median fibrosis degree measured by ARFI in all patients was significantly decreased after $\mathrm{HCV}$ eradication with $100 \%$ success in cure rate and $16.5 \%$ of patients failed to regress fibrosis.

Conclusion: A disappointing percentage (16.5\%) failure in fibrosis regression although reaching a sustained

Keywords: Hepatitis C virus, Sustained virological response, Liver cirrhosis.

Handling, parceling, and digestion of supplements give the vitality expected to the recently referenced procedures and are thusly among the liver's most basic capacities. In addition, the liver store glucose as glycogen, with nourishing, and collect glucose by means of the gluconeogenesis pathway, considering fasting. The liver oxidizes lipids yet can likewise process abundance lipid for discharge to and capacity in different tissues, for example, fat tissues ${ }^{(2)}$.

At long last, the liver is a noteworthy handler of protein and amino corrosive digestion as it is in charge of most of proteins discharged in the blood, the preparing of amino acids for vitality, and transfer of nitrogenous waste from protein debasement as urea digestion ${ }^{(3)}$.

Liver disappointment from any number of sources (for example viral disease, over sustenance, or oncologic weight) is a worldwide medical issue. Emphasize that knowledge into hepatic pathologies and potential helpful roads to treat these conditions requires a comprehension of the advancement and physiology of hepatic capacities ${ }^{(2)}$.

The World Health Organization (WHO) has discovered that Egypt has the most elevated commonness of the Hepatitis $\mathrm{C}$ infection (HCV) on the planet, with roughly 22 percent of Egyptian blood givers testing positive for the lethal ailment. As per $\mathrm{HCV}$ advocate, the fundamental driver of presentation in Egypt has all the earmarks of being because of deficient contamination control practices and infusion treatment, for example, blood transfusions. Ailing in foundation to manage the infection, Egypt experiences an especially high dreariness and death rate, with 40,000 biting the dust from the illness every year. It is evaluated that around 15 million Egyptians at present experience the ill effects of Hepatitis C. Consistently there are 170,000 to 200,000 new HCV cases. Hepatitis $\mathrm{C}$ infection (HCV) is a hepatotropic infection and a noteworthy reason for constant hepatitis and liver malady around the world. Introductory connections between $\mathrm{HCV}$ virions and hepatocytes are required for gainful viral disease and commencement of the viral life cycle. The accessibility of the immediate acting antivirals which are basic and middle of the road treatments for hepatitis $\mathrm{C}$ infection $(\mathrm{HCV})$ contamination with reactions $>95 \%$ is one of the best medicinal advances in decades, offering a chance to turn around the rising weight due to $\mathrm{HCV}$ and endeavor towards HCV disposal. A key test pushing ahead will be to guarantee that the individuals who are undiscovered are caused mindful of their contamination, to get HCV treatment and accomplish viral fix ${ }^{(4)}$.

Liver fibrosis is the last basic pathway of ceaseless or iterative liver harm. Progressed perpetual fibrosis is portrayed as cirrhosis with lost design and utilitarian disappointment and the advancement of dangerous difficulties. In any case, convincing investigations demonstrates that if the damage is 
expelled liver fibrosis is reversible. Hepatocytes initiated hepatic stellate cells, endothelial and resistant cells, especially macrophages, collaborate in the foundation and goals of liver fibrosis. Liver illness is a noteworthy neglected therapeutic need; as of now, the sole methodologies are the withdrawal of the harmful improvement and liver transplantation ${ }^{(5)}$.

This investigation will follow the fibrosis level in patients who restored with full portion of direct acting antivirals with the lab and radiological (by Acoustic radiation power driving forces "ARFI") nonintrusive markers of fibrosis.

\section{AIM OF THE WORK}

The aim of this study was to assess the effect of achieving a sustained virological response (SVR) after therapy with direct acting antiviral agents on grade of liver fibrosis (at $12 \& 24$ weeks after completion of therapy for HCV infection (i.e. SVR 12 \& SVR 24) compared with fibrosis grade before treatment initiation.

\section{PATIENTS AND METHODS}

This prospective observational cohort study was conducted during the period between June 2017 and March 2019.

Ethical approval and Informed Consent: The study was approved by the medical ethics committee of Al-Azhar University Hospitals and a written informed consent is obtained from all patients.

Informed consents were obtained from all participating patients before being admitted to the clinical study. An informed consent document, in Arabic language, contains all required elements and specifies [Form 1]. The patient's consent confirmed by the personally dated signature of the patient and by the personally dated signature of the person conducting the informed consent. Patients who are unable to read, oral presentation and explanation of the written informed consent form supplied to patients takes place in the presence of a witness [Form 2]. Consent is confirmed by the personally dated signature of the patient or by a local legally recognized alternative (e.g., the patient's thumbprint or mark). The investigator did not undertake any measures for the clinical study until valid consent has been obtained.

The subjects were divided into 3 groups: Group 1: includes 20 non-cirrhotic chronic HCV individuals achieved SVR after treatment using daily fixed-dose combination of paritaprevir $(150 \mathrm{mg})+$ ritonavir $(100 \mathrm{mg})+$ ombitasvir $(25 \mathrm{mg})$ and weightbased ribavirin Group 2: includes 20 non-cirrhotic chronic HCV individuals achieved SVR after treatment using daily fixed-dose combination of sofosbuvir 400 $\mathrm{mg}+$ ledipasvir $90 \mathrm{mg}$ Group 3: includes 20 noncirrhotic chronic HCV individuals achieved SVR after treatment using daily fixed-dose combination of sofosbuvir $400 \mathrm{mg}+$ Daclatasvir $60 \mathrm{mg}$ Each individual has been assessed at 3 time points which were: 0 point ( before the start of treatment) SVR 12 (sustained virological response 12) "12 weeks after treatment completion" SVR 24 (sustained virological response 24) "24 weeks after treatment completion" at Al-Azhar (Al-Hussein) Hospital and National Search Institute in Cairo.

Exclusion criteria were: Patients with liver cirrhosis (F4), hepatocellular carcinoma and malignancy as well as liver metastasis were excluded.

\section{Procedure}

Laboratory investigations Collection of Blood Samples for laboratory Tests: $4 \mathrm{ml}$ of venous blood were withdrawn aseptically into a sterile disposable syringe from every patient and control. Then divided to the following; $2 \mathrm{ml}$ of blood were added to ethylene diamine tetra acetic acid (EDTA) tubes for estimation of complete blood picture (CBC). The remaining $2 \mathrm{ml}$ of blood were collected on plain tubes and centrifuged for 10 minutes at 1500 revolutions per minute (rpm), a part of serum is separated in aliquots for the rest is used for AST, ALT, total and direct Billirubin, Prothrombin Time, I.N.R., Alpha fetoprotien (AFP), serum Albumin and serum creatinine measurement.

\section{Methods}

The following investigations were performed to all study patients: CBC: using Beckman Coulter Counter (HmX Hematology Analyzer, Coulter Corporation, Miami, FI 33116-9015). AST, ALT, total and direct Bilirubin, Prothrombin Time, I.N.R., serum Albumin, alpha fetoprotein and serum creatinine were measured on Synchron CX9 autoanalyzer (Beckman Instruments Inc.; Scientific Instruments Division, Fullerton, CA 92634, 3100). Assessment of fibrosis degree by acoustic radiation force impulse (ARFI).

Principle of the test: Acoustic radiation force impulse (ARFI), a valid method to assess liver fibrosis. This imaging technology permits evaluation of liver stiffness in a region of interest (ROI) involving mechanical excitation of tissue using short-duration ( $\sim 262 \mu \mathrm{s})$ acoustic pulses while performing a real-time B-mode conventional hepatic U/S. Results are expressed in $(\mathrm{m} / \mathrm{s})$. A critical advantage is the possibility to choose the representative area of interest avoiding large vessels and ribs. comperhensing the level of fibrosis at 3 points of assessment with laboratory results assessment simultaneously. ARFI measurements will be performed with a Siemens Acuson S3000 Virtual Touch ultrasound system (Siemens AG, Erlangen, Germany) with a 6CI transducer. In each patient 10 valid ARFI measurements were performed in liver and the median values were calculated, the results being expressed in 
meters $/ \mathrm{second}(\mathrm{m} / \mathrm{s})$, results are calculated according to the following values.

\section{Statistical methods}

IBM SPSS statistics (V. 22.0, IBM Corp., USA, 2013) was used for data analysis. Data were expressed as Median Percentiles for quantitative nonparametric measures.

The following tests were done: Comparison between two independent groups for non-parametric data using Wilcoxon Rank Sum test. Comparison between more than 2 patient groups for non-parametric data using Kruskall Wallis test. Ranked Sperman correlation test to study the possible association between each two variables among each group for nonparametric data. The probability of error at 0.05 was considered significant; while at 0.01 and 0.001 are highly significant. P- value: level of significance: $\mathrm{P}>0.05$ : Non significant (NS) $\mathrm{P}<0.05$ : Significant $(\mathrm{S})$ $\mathrm{P}<0.01$ : Highly significant (HS).

Diagnostic validity test: It includes: The diagnostic sensitivity: It is the percentage of diseased cases truly diagnosed (TP) among total diseased cases $(\mathrm{TP}+\mathrm{FN})$. The diagnostic specificity: It is the percentage of non-diseased truly excluded by the test (TN) among total non-diseased cases $(\mathrm{TN}+\mathrm{FP})$. The predictive value for $a+v e$ test: It is the percentage of cases truly diagnosed among total positive cases. The predictive value for a -ve test: It is the percentage of cases truly negative among total negative cases. The efficacy or the diagnostic accuracy of the test: It is the percentage of cases truly diseased plus truly nondiseased among total cases.

\section{RESULTS}

Table (1): ARFI results

\begin{tabular}{|c|c|c|c|c|c|c|}
\hline & \multicolumn{3}{|c|}{ ARFI } & & & \\
\hline \multirow{4}{*}{ Group 1} & Time & $\mathbf{P}$ & Sig. & \multicolumn{2}{|c|}{ P - Sig. } & $\mathbf{P}$ \\
\hline & $0-12$ & 0.022 & HS & & & \\
\hline & $12-24$ & 0.007 & HS & 0.001 & HS & \\
\hline & 0 - 24 & 0.003 & HS & & & \\
\hline & Time & $\mathbf{n}$ & Sig & & & \\
\hline & 0 - 12 & 0.048 & $\mathrm{~S}$ & & & \\
\hline Group 2 & $12-24$ & 0.05 & $\mathbf{S}$ & 0.05 & $\mathbf{S}$ & $S$ \\
\hline & $0-24$ & 0.049 & $\mathbf{S}$ & & & \\
\hline & & & & & & \\
\hline & Time & p & Sig. & & & \\
\hline Groun 3 & 0 - 12 & 0.043 & $\mathbf{S}$ & & & \\
\hline Group 3 & $12-24$ & 0.049 & $\mathbf{S}$ & 0.049 & $\mathbf{S}$ & \\
\hline & $0-24$ & 0.045 & $\mathbf{S}$ & & & \\
\hline
\end{tabular}

This table shows the significance of ARFI readings through the 3-point assessment, showing significant improvement with sustained virological response in all groups (P value 0.05).

Table (2): FIB-4 results

\begin{tabular}{|c|c|c|c|c|c|c|}
\hline \multirow{5}{*}{ Group 1} & \multicolumn{3}{|c|}{ FIB-4 } & & & \\
\hline & Time & p & Sig. & \multicolumn{2}{|c|}{ P - Sig. } & $\mathbf{P}$ \\
\hline & $0-12$ & 0.022 & $\mathbf{S}$ & \multirow{3}{*}{0.022} & \multirow{3}{*}{$\mathbf{S}$} & \multirow{12}{*}{$\begin{array}{c}\mathrm{S} \\
\mathbf{0 . 0 2 5}\end{array}$} \\
\hline & $12-24$ & 0.028 & $\mathbf{S}$ & & & \\
\hline & 0 - 24 & 0.012 & $\mathbf{S}$ & & & \\
\hline & & & & & & \\
\hline \multirow{4}{*}{ Group 2} & Time & $\mathbf{p}$ & Sig. & \multicolumn{2}{|c|}{ P - Sig. } & \\
\hline & 0 - 12 & 0.026 & $\mathrm{~S}$ & \multirow{3}{*}{0.023} & \multirow{3}{*}{$\mathbf{S}$} & \\
\hline & $12-24$ & 0.024 & $\mathbf{S}$ & & & \\
\hline & $0-24$ & 0.025 & S & & & \\
\hline \multirow{4}{*}{ Group 3} & Time & D & Sig. & \multicolumn{2}{|c|}{ P - Sig. } & \\
\hline & $0-12$ & 0.024 & $\mathrm{~S}$ & & & \\
\hline & $12-24$ & 0.034 & $\mathbf{S}$ & 0.028 & $\mathbf{S}$ & \\
\hline & $0-24$ & 0.021 & $\mathbf{S}$ & & & \\
\hline
\end{tabular}

Table (2) shows positive correlation between sustained virological response and FIB-4 in all studied groups $(P$ value $0.025)$ 
Table (3): APRI results

\begin{tabular}{|c|c|c|c|c|c|c|}
\hline & \multicolumn{3}{|c|}{ APRI } & & & \multirow{3}{*}{ p } \\
\hline \multirow{4}{*}{ Group 1} & Time & p & Sig. & \multicolumn{2}{|c|}{ P - Sig. } & \\
\hline & $0-12$ & 0.008 & HS & \multirow{3}{*}{0.001} & \multirow{3}{*}{ HS } & \\
\hline & $12-24$ & $\mathbf{0}$ & HS & & & \multirow{12}{*}{$\begin{array}{c}\text { HS } \\
0.001\end{array}$} \\
\hline & $0-24$ & 0.007 & $\mathbf{S}$ & & & \\
\hline & 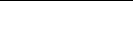 & & & & & \\
\hline \multirow{4}{*}{ Group 2} & Time & p & Sig. & \multicolumn{2}{|c|}{ P - Sig. } & \\
\hline & $0-12$ & 0 & HS & \multirow{3}{*}{0.001} & \multirow{3}{*}{ HS } & \\
\hline & $12-24$ & 0 & HS & & & \\
\hline & $0-24$ & 0.002 & HS & & & \\
\hline & & & & & & \\
\hline \multirow{4}{*}{ Group 3} & Time & p & Sig. & \multicolumn{2}{|c|}{ P - Sig. } & \\
\hline & $0-12$ & 0.001 & HS & & & \\
\hline & $12-24$ & 0.001 & HS & 0.02 & $\mathbf{S}$ & \\
\hline & $0-24$ & 0.04 & $\mathrm{~S}$ & & & \\
\hline
\end{tabular}

The above table shows significant improvement of APRI score with CHC eradication with sustained virological response in all groups $(P \varangle 0.001)$

Table (4): INR results

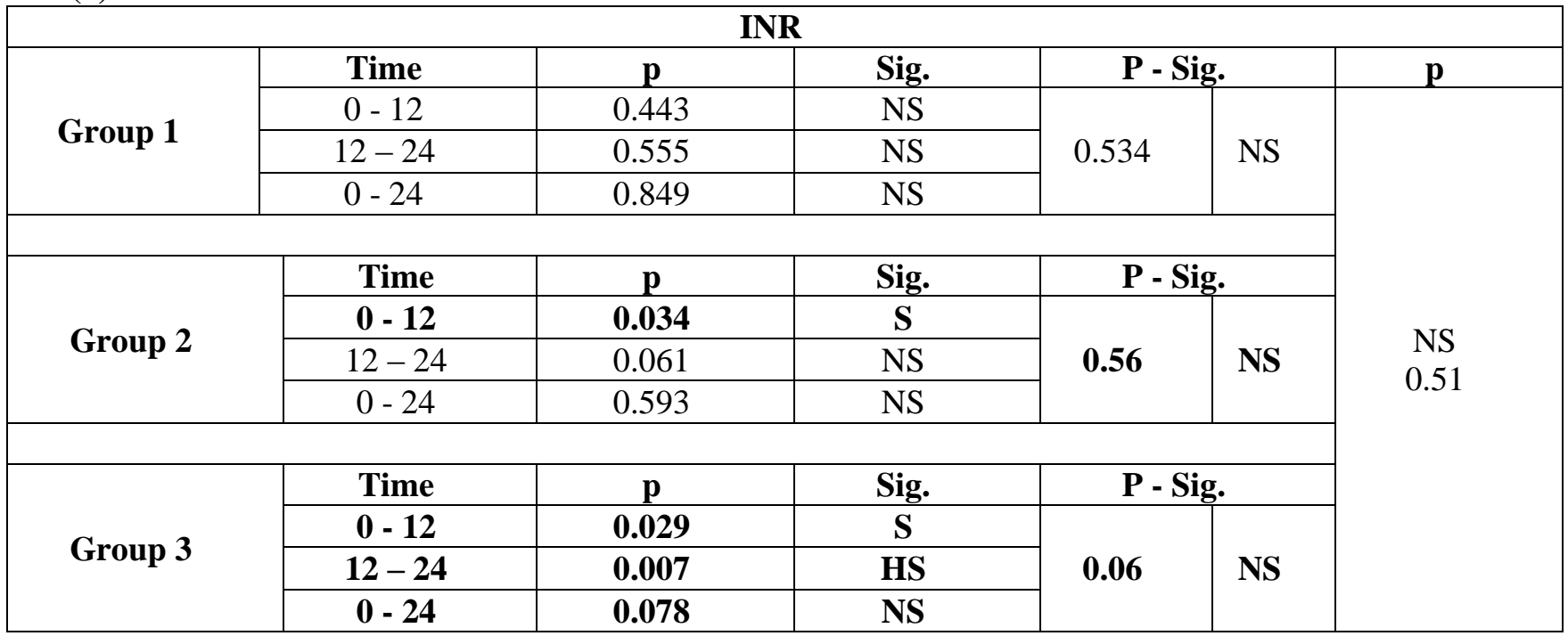

Non-significant correlation observed between INR and sustained virological response after direct acting HCV antivirals eradication in all study groups $(P>0.05)$

Table (5): Albumin results

\begin{tabular}{|c|c|c|c|c|c|c|}
\hline 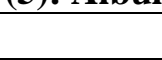 & \multicolumn{3}{|c|}{ Albumin } & & & \\
\hline \multirow{4}{*}{ Group 1} & Time & p & Sig. & \multicolumn{2}{|c|}{ P - Sig. } & $\mathbf{P}$ \\
\hline & $0-12$ & 0.04 & $\mathbf{S}$ & & & \\
\hline & $12-24$ & 0.194 & NS & 0.41 & NS & \\
\hline & $0-24$ & 0.908 & $\mathrm{NS}$ & & & \\
\hline & & & & & & \\
\hline & Time & p & Sig. & & & \\
\hline & $0-12$ & 0.643 & $\mathrm{NS}$ & & & \\
\hline Group 2 & $12-24$ & 0.189 & NS & 0.594 & NS & NS \\
\hline & 0 - 24 & 0.015 & $\mathbf{S}$ & & & \\
\hline & & & & & & \\
\hline & Time & p & Sig. & & & \\
\hline Groun 3 & $0-12$ & 0.503 & NS & & & \\
\hline Group 3 & $12-24$ & 0.534 & $\mathrm{NS}$ & 0.53 & NS & \\
\hline & $0-24$ & 0.154 & $\mathrm{NS}$ & & & \\
\hline
\end{tabular}

Table 5 shows no significance between HCV eradication and serum albumin levels in our study groups $(P>0.05)$ 
Table (6): Liver enzymes results

\begin{tabular}{|c|c|c|c|c|c|c|}
\hline \multirow{8}{*}{ Group 1} & \multirow{4}{*}{$\frac{5}{2}$} & Time & $\mathbf{p}$ & Sig. & \multicolumn{2}{|c|}{ P - Sig. } \\
\hline & & 0 - 12 & 0 & HS & \multirow{3}{*}{0.001} & \multirow{3}{*}{ HS } \\
\hline & & $12-24$ & 0 & HS & & \\
\hline & & $0-24$ & $\mathbf{0 . 0 3 3}$ & $\mathbf{S}$ & & \\
\hline & \multirow{4}{*}{$\frac{5}{4}$} & Time & $\mathbf{p}$ & Sig. & \multicolumn{2}{|c|}{ P - Sig. } \\
\hline & & 0 - 12 & 0.001 & HS & \multirow{3}{*}{0.001} & \multirow{3}{*}{ HS } \\
\hline & & $12-24$ & 0 & HS & & \\
\hline & & 0 - 24 & 0.01 & $\mathbf{S}$ & & \\
\hline \multirow{8}{*}{ Group 2} & \multirow{4}{*}{ 㝵 } & Time & $\mathbf{p}$ & Sig. & \multicolumn{2}{|c|}{ P - Sig. } \\
\hline & & 0 - 12 & 0.002 & HS & \multirow{3}{*}{0.001} & \multirow{3}{*}{ HS } \\
\hline & & $12-24$ & 0.001 & HS & & \\
\hline & & $0-24$ & 0.003 & HS & & \\
\hline & \multirow{4}{*}{$\frac{5}{4}$} & Time & $\mathbf{p}$ & Sig. & \multicolumn{2}{|c|}{ P - Sig. } \\
\hline & & 0 - 12 & 0 & HS & \multirow{3}{*}{0.001} & \multirow{3}{*}{ HS } \\
\hline & & $12-24$ & $\mathbf{0}$ & HS & & \\
\hline & & $0-24$ & 0.002 & HS & & \\
\hline \multirow{8}{*}{ Group 3} & \multirow{4}{*}{ 妾 } & Time & $\mathbf{p}$ & Sig. & \multicolumn{2}{|c|}{ P - Sig. } \\
\hline & & 0 - 12 & $\mathbf{0}$ & HS & \multirow{3}{*}{$\mathbf{0 . 0 3}$} & \multirow{3}{*}{$\mathbf{S}$} \\
\hline & & $12-24$ & $\mathbf{0}$ & HS & & \\
\hline & & $0-24$ & 0.067 & $\mathrm{NS}$ & & \\
\hline & \multirow{4}{*}{$\frac{5}{4}$} & Time & $\mathbf{p}$ & Sig. & \multicolumn{2}{|c|}{ P - Sig. } \\
\hline & & 0 - 12 & $\mathbf{0}$ & HS & \multirow{3}{*}{0.001} & \multirow{3}{*}{ HS } \\
\hline & & $12-24$ & $\mathbf{0}$ & HS & & \\
\hline & & $0-24$ & 0.057 & NS & & \\
\hline
\end{tabular}

The above table shows the correlation between elimination of HCV and serum transaminases (alanine aminotransferase (ALT) and aspartate aminotransferase (AST)) in the three groups of our study which appears to be highly significant nearly for all groups. $(P<0.001)$

Table (7): Bilirubin results

\begin{tabular}{|c|c|c|c|c|c|c|}
\hline 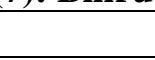 & & & ubin & & & \\
\hline \multirow{8}{*}{ Group 1} & \multirow{4}{*}{$\mathbf{T}$} & Time & $\mathbf{p}$ & Sig. & \multicolumn{2}{|c|}{ P - Sig. } \\
\hline & & $0-12$ & 0.001 & HS & \multirow{3}{*}{0.001} & \multirow{3}{*}{ HS } \\
\hline & & $12-24$ & $\mathbf{0}$ & HS & & \\
\hline & & $0-24$ & 0.001 & HS & & \\
\hline & \multirow{4}{*}{ D } & Time & p & Sig. & \multicolumn{2}{|c|}{ P - Sig. } \\
\hline & & $0-12$ & 0.005 & HS & \multirow{3}{*}{0.001} & \multirow{3}{*}{ HS } \\
\hline & & $12-24$ & 0.001 & HS & & \\
\hline & & $0-24$ & 0.003 & HS & & \\
\hline \multirow{8}{*}{ Group 2} & \multirow{4}{*}{$\mathbf{T}$} & Time & $\mathbf{p}$ & Sig. & \multicolumn{2}{|c|}{ P - Sig. } \\
\hline & & $0-12$ & 0 & HS & \multirow{3}{*}{0.001} & \multirow{3}{*}{ HS } \\
\hline & & $12-24$ & $\mathbf{0}$ & HS & & \\
\hline & & $0-24$ & 0.006 & HS & & \\
\hline & \multirow{4}{*}{ D } & Time & $\mathbf{p}$ & Sig. & \multicolumn{2}{|c|}{ P - Sig. } \\
\hline & & $0-12$ & 0 & HS & \multirow{3}{*}{0.001} & \multirow{3}{*}{ HS } \\
\hline & & $12-24$ & 0.001 & HS & & \\
\hline & & $0-24$ & 0.003 & HS & & \\
\hline \multirow{8}{*}{ Group 3} & \multirow{4}{*}{$\mathbf{T}$} & Time & p & Sig. & \multicolumn{2}{|c|}{ P - Sig. } \\
\hline & & $0-12$ & 0.025 & $\mathbf{S}$ & \multirow{3}{*}{0.001} & \multirow{3}{*}{ HS } \\
\hline & & $12-24$ & 0.001 & HS & & \\
\hline & & $0-24$ & 0.007 & HS & & \\
\hline & \multirow{4}{*}{ D } & Time & p & Sig. & \multicolumn{2}{|c|}{ P - Sig. } \\
\hline & & $0-12$ & 0.073 & NS & \multirow{3}{*}{0.079} & \multirow{3}{*}{ NS } \\
\hline & & $12-24$ & 0.014 & $\mathbf{S}$ & & \\
\hline & & $0-24$ & 0.108 & NS & & \\
\hline
\end{tabular}

Table 7 shows the correlation between sustained virological response and serum bilirubin (Total and direct) in the three groups of our study which appears to be highly significant for all groups $(P<0.001)$ with non-significant correlation of direct bilirubin in group 3 ( $P$ value of 0.079) 
Table (8): AFP results

\begin{tabular}{|c|c|c|c|c|c|}
\hline \multirow{5}{*}{ Group 1} & \multicolumn{3}{|c|}{ AFP } & \multirow{2}{*}{\multicolumn{2}{|c|}{ P - Sig. }} \\
\hline & Time & $\mathbf{p}$ & Sig. & & \\
\hline & $0-12$ & 0.062 & NS & \multirow{3}{*}{0.95} & \multirow{3}{*}{ NS } \\
\hline & $12-24$ & 0.191 & NS & & \\
\hline & $0-24$ & 0.033 & $\mathbf{S}$ & & \\
\hline & & & & & \\
\hline \multirow{4}{*}{ Group 2} & Time & $\mathbf{p}$ & Sig. & \multicolumn{2}{|c|}{ P - Sig. } \\
\hline & $0-12$ & 0.201 & NS & \multirow{3}{*}{0.094} & \multirow{3}{*}{ NS } \\
\hline & $12-24$ & 0.044 & $\mathbf{S}$ & & \\
\hline & $0-24$ & 0.086 & $\mathrm{NS}$ & & \\
\hline \multirow{4}{*}{ Group 3} & Time & p & Sig. & \multicolumn{2}{|c|}{ P - Sig. } \\
\hline & $0-12$ & 0.603 & $\mathrm{NS}$ & \multirow{3}{*}{0.355} & \multirow{3}{*}{ NS } \\
\hline & $12-24$ & 0.198 & $\mathrm{NS}$ & & \\
\hline & $0-24$ & 0.277 & NS & & \\
\hline
\end{tabular}

Table 8 shows no correlation between HCV elimination and AFP levels in all study groups $(P>0.05)$.

\section{DISCUSSION}

Liver cirrhosis ultimately prevents the liver from functioning properly. Cirrhosis can eventually lead to end-stage liver disease and liver failure. Liver fibrosis results from chronic damage of liver tissues in conjunction with the accumulation of extra cellular matrix $(\mathrm{ECM})$ proteins, which is a characteristic of most types of chronic liver diseases ${ }^{\left({ }^{6}\right)}$.

Hepatic fibrosis was thought to be a passive and irreversible process due to the collapse of the hepatic parenchyma and its substitution with a collagen-rich tissue ${ }^{(7)}$. Currently, it is considered a model of the wound-healing response to chronic liver injury ${ }^{(8)}$.

Most patients who receive a diagnosis of $\mathrm{CHC}$, even those without SVR, benefit from antiviral treatments in terms of the reversal of necroinflammation and fibrosis during and after the treatment course $^{(9)}$.

In the present work, we non-invasively evaluate the degree of liver fibrosis in 60 non-cirrhotic subjects whom successfully eradicated $\mathrm{HCV}$ with direct acting antivirals which were divided into 3 groups.

G 1 (20 individuals treated by daily fixed-dose combination of paritaprevir $(150 \mathrm{mg})+$ ritonavir $(100$ $\mathrm{mg})+$ ombitasvir $(25 \mathrm{mg}$ ) and weight-based ribavirin).

G 2 (includes 20 individuals treated by daily fixed-dose combination of sofosbuvir $400 \mathrm{mg}+$ ledipasvir $90 \mathrm{mg}$ )

G 3 (include 20 patients 20 individuals treated by daily fixed-dose combination of sofosbuvir $400 \mathrm{mg}$ + Daclatasvir $60 \mathrm{mg}$ ).

For each studied subject, detection of hepatitis C RNA by PCR, ARFI, APRI, FIB-4, assessment of liver function tests \& chemistry, $\alpha$-fetoprotein (AFP) and complete blood picture were assessed at 3 points: $\mathbf{0}$ point ( at the start of treatment) SVR 12 (sustained virological response 12) "12 weeks after treatment completion" SVR 24 (sustained virological response 24) "24 weeks after treatment completion".
By measuring liver stiffness non-invasively by acoustic radiation force impulses (ARFI) of all subjects more fibrosis regression was observed in groups $1(P<$ $0.001)$ comparing to regression levels in group $2(P<$ $0.05) \& 3(P<0.05)$.

This indicates a highly positive correlation between successful eradication of HCV by oral direct acting antivirals and fibrosis regression with the highest positive correlation between ARFI and group 1 (daily fixed-dose combination of paritaprevir $(150 \mathrm{mg})+$ ritonavir $(100 \mathrm{mg})+$ ombitasvir $(25 \mathrm{mg})$ and weightbased ribavirin) by Wilcoxon Rank test when comparing with the other study groups. Failure of fibrosis regression after sustained virological response was observed in 6 cases $(16.5 \%)$ of all study group individuals.

Sheng-Hung Chen et al. ${ }^{(10)}$ conducted a study included a total of 256 patients, of which $219(85.5 \%)$ achieved SVR. The paired liver stiffness (LS) values using ARFI declined significantly from baseline to SVR visit in all groups except the non-responder subgroup (n $=10)$. Baseline LS $(P<0.0001)$ were identified as independent factors that explained the LS declines. Likewise, the baseline FIB-4 $(P<0.0001)$ and APRI $(P<0.0001)$ values independently explained the declines in the FIB-4 index and APRI, respectively.

Similar results were reported by Jason et al. ${ }^{(11)}$ who found that among the 56 patients prior to SVR, thirty-three patients (59\%) had improved by at least one stage and 27 patients (48\%) had improved by at least two predicted stages of fibrosis after SVR. The median time to improvement was one year.

In another study conducted by Dolmazashvili et al. ${ }^{\text {(12) }}$, fibrosis decreased from the baseline median value of 16.9 (interquartile range: $11.8-27.7$ ) $\mathrm{kPa}$ to a post-treatment week 24 score of 11.9 (interquartile range: $8.2-20.9) \mathrm{kPa}(P<0.0001)$. Of a total of 304 patients, $198(65.1 \%)$ achieved at least a 20\% reduction in liver fibrosis. In multivariate logistic regression 
analysis, sustained virological response (SVR) was associated significantly with this reduction $(P<0.0001)$.

Rayes et al. ${ }^{(13)}$ found similar results in their study as they noticed percentage reduction in fibrosis with $95 \%$ confidence intervals (all patients): 20.04 +/$9.68 \%$. There is a statistically significant reduction in liver fibrosis after treatment with DAAs". The study included only 18 patients.

In our study the FIB- 4 index was calculated as AST $\left(\right.$ IU/L) $\times$ age $($ years $) /$ platelet count $\left(10^{9} / \mathrm{L}\right) \times$ ALT (IU/L). FIB-4 index shows significant positive changes in all study groups $(P<.0 .05)$.

In propensity score-adjusted analyses, we observed significant changes in FIB4 score that varied with treatment and response to treatment. In patients achieving SVR, FIB4 scores decreased sharply, remaining significantly lower over the 10 -year period $(P<.001)^{(14)}$

In a study conducted by Yu-Chi et al. ${ }^{(15)}$ a total of 213 patients with complete treatment were enrolled. All patients achieved sustained virological response at 12 weeks (SVR12). FIB-4 decreased significantly at the time of SVR12 $(P<0.001)$. Compared with follow-up period FIB-4 decreased rapidly during DDAs. Multivariate analyses showed that higher baseline FIB4 were associated with greater reductions at the time of SVR12.

Regarding the AST to platelets ratio index (APRI) was calculated as (AST [IU/L]/upper limit of normal AST $[\mathrm{IU} / \mathrm{L}]) \times 100 /$ platelet count $\left(10^{9} / \mathrm{L}\right)$. In our study subjects in all groups, highly positive significant correlation ( $P$ value $<0.001)$ was observed between successful HCV eradication and APRI with ( $P$ value < 0.001 group 1$),(P<0.001$ for group 2$),(P=002$. for group 3)

These results are consistent with Jason et al. ${ }^{(11)}$ in the cirrhosis group of the repeat biopsy subset, APRI scores decreased $(P=0.04)$ and FIB- 4 scores $(P=0.02)$. In the F3 group, APRI scores $(P=0.07)$ and FIB- 4 scores $(P=0.14)$.

A total of 256 patients were included, of which $219(85.5 \%)$ achieved SVR. The paired liver stiffness (LS) values using ARFI declined significantly from baseline to SVR visit in all groups except the nonresponder subgroup $(\mathrm{n}=10)$. Baseline LS $(P<0.0001)$ were identified as independent factors that explained the LS declines. Likewise, the baseline FIB-4 $(P<0.0001)$ and APRI $(P<0.0001)$ values independently explained the declines in the FIB-4 index and APRI, respectively (10).

Complete hemodynamic response and fibrosis regression occur in more than half and one-third of patients achieving SVR, respectively $(P<0.0001, P<$ 0.0001 , respectively), and must be another target in cirrhotic patients with SVR ${ }^{(16)}$.

By observing the levels of transaminases (aspartate aminotransferase (AST) and alanine aminotransferase (ALT)) and bilirubin levels in the sera of our subjects we found a strong significant correlation between treatment of $\mathrm{CHC}$ and improvement of aminotransferases and bilirubin levels in all subjects of the studied groups $(P<0.0001, P<0.0001, P<0.0001$ for ALT,AST \& bilirubin respectively).

These results are consistent with Jason et al. ${ }^{(11)}$ where mean alanine aminotransferase (ALT) changed from 122 to $35(P<0.001)$, aspartate aminotransferase (AST) from 90 to 28 ( $P<0.001)$. In the $\mathrm{F} 3$ group, mean ALT changed from 114 to 34 ( $P<0.001)$, AST from 81 to $27(P<0.001)$.

In another study done by Sheng-Hung et al. ${ }^{(10)}$ a total of 256 patients were included, of which 219 $(85.5 \%)$ achieved SVR. Serum ALT, AST and bilirubin levels were significantly $(P<0.0001)$ correlated with the liver stiffness regression estimated.

In the present work sequential changes in laboratory data were:

(a) Aspartate aminotransferase decreased over time, and there were significant differences between baseline and EOT and between EOT and SVR24 $(P<0.001$ by the Friedman test). (b) Alanine aminotransferase decreased over time, and there were significant differences between baseline and EOT and between EOT and SVR24 $(P<0.001$ by the Friedman test). (d) Total bilirubin significantly increased from baseline to EOT $(P<0.001)$ and significantly decreased from EOT to SVR24 $(P=0.002)(P<0.001$ by the Friedman test) which coincided with Toshifumi $\boldsymbol{e t}$ al. (17).

Observing the results of serum albumin and INR in study group, no significance were found between $\mathrm{CHC}$ eradication and serum albumin $(P=0.544)$ nor INR levels $(P=0.51)$, these results are consistent with Jason et al. (11) as they found no correlation between mean albumin (from 4 to $4.2, \mathrm{P}=$ $0.12)$ and mean INR $(P=0.12)$ and $\mathrm{CHC}$ eradication.

(c) Albumin increased over time, and there were significant differences between baseline and EOT and between EOT and SVR24 $(P<0.001$ by the Friedman test). DAA therapy resulted in an increase in albumin levels in SVR patients, which was significantly correlated with a decrease in AST levels. An increase in albumin levels was significantly correlated with a decrease in AST levels $(r=0.4729, P=0.0119)$. It is probable that the reduction of inflammation, but not by reduction of fibrosis, mainly caused an increase in albumin levels which coincided with Toshifumi $\boldsymbol{e t}$ al. (17) who found that mean serum levels of albumin positively correlate $(P<0.001)$ to $\mathrm{CHC}$ eradication "Sequential changes in laboratory data:

Regarding alpha-fetoprotein (AFP), there was no significant correlation between $\mathrm{CHC}$ eradication in sera of our subjects and alpha-fetoprotein (AFP) with $\mathrm{P}$ value of $0.95,0.094,0.355$ for groups $1,2 \& 3$ respectively.

These results were consistent with Toshiki $\boldsymbol{e t}$ al. (18) where levels of $\alpha$-fetoprotein (AFP) 
significantly decreased from baseline to EOT but showed no significant change between EOT and SVR24.

No significant difference in mean baseline AFP level was found between the triple and dual therapy groups $(8.8 \mathrm{ng} / \mathrm{mL} v s 7.8 \mathrm{ng} / \mathrm{mL})$. Among patients with a high-baseline AFP level $(\geq 10 \mathrm{ng} / \mathrm{mL})$, the decline in the AFP level was significantly higher in the triple therapy than in the dual therapy group (15.9 $\mathrm{ng} / \mathrm{mL}$ vs $1.6 \mathrm{ng} / \mathrm{mL}, P=0.037)^{(\mathbf{1 9})}$.

Miyaki et al. ${ }^{(20)}$ investigated the impact of direct antiviral (daclatasvir and asunaprevir) on $\mathrm{HCV}$ genotype $1 \mathrm{~b}$ treatment on liver function parameters and liver fibrosis markers in only 30 patients with chronic $\mathrm{HCV}, 26$ of them achieved SVR and the other four did not. They found that serum AFP was significantly improved by DAA therapy only in SVR patients $(P<0.001)$.

Tachi et al. (21) concluded significant independent predictive factors for regressed fibrosis after SVR were lower AFP levels at 24 weeks after end of treatment $(P=0.006)$. Lower post-treatment AFP levels and HCV genotype 2 significantly correlated with liver fibrosis regression after achieving SVR by interferon and ribavirin therapy

There was a significant decrease in AFP in patients with cirrhosis who achieved SVR with DAAs. Given a reduction in AFP after DAA treatment $(P<$ 0.001), AFP should be further studied as a screening modality for HCC in patients with cirrhosis ${ }^{(22)}$.

Regarding complete blood count of the subjects of our study, results show no significant correlation between post $\mathrm{CHC}$ eradication fibrosis regression and red cells count (RBCs), hemoglobin levels and total leucocytes count $(P>0.005)$.

These results are consistent with Koji et al. ${ }^{(19)}$; where there was no significant correlation between CHC eradication and hemoglobin levels $(\mathrm{P}=0.319)$ nor white cell count $(P=0.447)$ in study subjects.

Kelvin et al. (22) found no significant association between hemoglobin levels and post DAA $\mathrm{CHC}$ eradication was confirmed $(P=0.595)$.

Unexpectedly, we did not observe any difference in SVR rates between the hemoglobin $<13$ and $\geq 13 \mathrm{~g} / \mathrm{dL}$ groups (see Results section) or according to neutrophil counts ${ }^{(23)}$.

Angela et al. ${ }^{(16)}$ reported that only the eight patients with SVR underwent the final hemodynamic study and Fibroscan ${ }^{\circledR}$. The results were analyzed by intention-to-treat. In all patients, there was a statistically significant decrease $(\mathrm{p}<0.001)$ in hemoglobin, neutrophil and platelet levels.

Unfortunately, the results of Angela et al. ${ }^{(16)}$ were influenced by the fewer number of subjects (16) and the presence of cirrhosis (F4).

Assessment of the relation between fibrosis regression with $\mathrm{HCV}$ eradication and platelets count showed positive significance in group $1(P<0.005)$.
Unfortunately, no significant correlation was observed with group 2 and 3 ( $P=0.681, P=0.365$ respectively).

At 24 weeks after the end of treatment, platelet count was significant higher for patients with versus those without fibrosis regression ${ }^{(21)}$.

Sequential changes in laboratory data. (e) Platelet count showed no significant change between baseline and EOT $(P=1.000)$, but it significantly increased from EOT to SVR24 $(P<0.001)$. SVR was confirmed by the absence of serum hepatitis $\mathrm{C}$ virus RNA at 24 weeks after EOT (SVR24). ${ }^{(17)}$.

As expected, platelet count was found to be correlated with Fibroscan $(P=0.01)^{(16)}$.

Statistically significant changes occurred in liver chemistries and FIB- 4 scores between pre- SVR and the post- SVR values in the cirrhosis group, mean platelets from 133 to $153(P<0.001)^{(11)}$.

We did not observe any association between baseline platelet count below $130000 / \mu \mathrm{L}$ and SVR in the treatment-experienced patients in the present study.

Comparing all study groups to each other by Wilcoxon Rank Sum test, group (1) shows more significance regarding fibrosis regression by noninvasive ARFI comparing to other study groups.

While comparing all study groups by Wilcoxon Rank Sum test, regarding FIB-4 and APRI results, positive correlation of groups (1) and (2) appeared over group (3).

Using Wilcoxon Rank Sum test for comparing all study groups teach others, no group shows significant advantage over other groups regarding INR, serum albumin, bilirubin levels and complete blood count.

\section{CONCLUSION}

The present study concluded that with successful eradication of chronic hepatitis $\mathrm{C}$ virus infection using a 12 weeks regimen of various types of direct acting antivirals in a non-cirrhotic patients (daily fixed-dose combination of paritaprevir $(150 \mathrm{mg})+$ ritonavir $(100 \mathrm{mg})+$ ombitasvir $(25 \mathrm{mg})$ and weightbased ribavirin, daily fixed-dose combination of sofosbuvir $400 \mathrm{mg}+$ ledipasvir $90 \mathrm{mg}$ and lastly a daily fixed-dose combination of sofosbuvir $400 \mathrm{mg}+$ Daclatasvir $60 \mathrm{mg}$ ) and as presumed by acoustic radiation force impulses (ARFI), virological cure was associated with slow regression of fibrosis in $83.5 \%$ of the study population. A disappointing percentage (16.5\%) failure in fibrosis regression although reaching a sustained virological response.

\section{REFERENCES}

1. Tortora GJ, Derrickson BH (2008). Principles of Anatomy and Physiology, 12th ed.. John Wiley \& Sons.

2. Bechmann LP, Hannivoort RA, Gerken G, Hotamisligil GS, Trauner M, Canbay A (2012): The interaction of hepatic lipid and glucose metabolism in liver diseases. J Hepatol.,56:952-964 
3. Hijmans BS, Grefhorst A, Oosterveer MH, Groen AK (2014): Zonation of glucose and fatty acid metabolism in the liver: mechanism and metabolic consequences. Biochimie, 96:121-129.

4. Schiff ER, Maddrey WC, Sorrell MF (2013): Schiff's Diseases of the Liver. Oxford, UK: Wiley-Blackwell.

5. Compana L, Iredale JP (2017): Regression of liver fibrosis, 37(1):1-10.

6- Friedman SL (2003): Liver fibrosis - from bench to bedside. J. Hepatol., 38(1): S38-S53

7. Popper H, Uenfriend S (1970): Hepatic fibrosis. Correlation of biochemical and morphologic investigations. Am. J. Med., 49:707-721

8. Albanis E, Friedman SL (2001): Hepatic fibrosis. Pathogenesis and principles of therapy. Clin. Liver Dis., 5:315-334, v-vi

9. Gonzalez HC, Duarte-Rojo A (2016): Virologic cure of hepatitis C: Impact on hepatic fibrosis and patient outcomes. Curr Gastroenterol Rep., 18: 32.

10. Sheng-Hung $\mathrm{C}$, Hsueh-Chou L, I-Ping $\mathrm{C}$ et al. (2018): Changes in liver stiffness measurement using acoustic radiation force impulse elastography after antiviral therapy in patients with chronic hepatitis C. https://doi.org/10.1371/journal.pone.0190455.

11. Jason JP, Fei B, Emma D et al. (2018): Morphometry confirms fibrosis regression from sustained virologic response to direct- acting antivirals for hepatitis C. Hepatol Commun., 2(11): 1320-1330.

12. Dolmazashvili E, Abutidze A, Chkhartishvili $\mathbf{N}$ et al. (2017): Regression of liver fibrosis over a 24 -week period after completing direct-acting antiviral therapy in patients with chronic hepatitis $\mathrm{C}$ receiving care within the national hepatitis $\mathrm{C}$ elimination program in Georgia: results of hepatology clinic HEPA experience.2017. Eur J Gastroenterol Hepatol.,29(11):1223-1230.

13. Rayes J, Sebastiani G (2018): A190 regression of liver fibrosis after successful all oral antiviral therapy in $\mathrm{HCV}$ cirrhosis: a pilot study employing transient elastography and controlled attenuation parameter (cap). Journal of the Canadian Association of Gastroenterology, 1: 331.
14. Mei L, Jia L, Talan $Z$ et al. (2016): Serum biomarkers indicate long-term reduction in liver fibrosis in patients with sustained virological response to treatment for $\mathrm{HCV}$ infection. Clin Gastroenterol Hepatol.,14(7): 1044-1055.e3.

15. Yu-Chi L, Tsung-Hui H, Chao-Hung H et al. (2019): The change in liver stiffness, controlled attenuation parameter and fibrosis-4 index for chronic hepatitis $\mathrm{C}$ patients with direct-acting antivirals. https://doi.org/10.1371/journ-al.pone.0214323

16. Angela $P$, Joaquín C, María JLA et al. (2017): Influence of sustained viral response on the regression of fibrosis and portal hypertension in cirrhotic $\mathrm{HCV}$ patients treated with antiviral triple therapy. http://dx.doi.org/10.17235/reed. 2016.4235/2016

17. Toshifumi T, Takashi K, Hidenori $T$ et al. (2017): Improvement of liver stiffness in patients with hepatitis $\mathrm{C}$ virus infection who received direct- acting antiviral therapy and achieved sustained virological response. J Gastroenterol Hepatol. doi:10.1111/jgh.13788.

18. Toshiki K, Senju H, Naoto $K$ et al. (2017): Increase in albumin by daclatasvir/asunaprevir therapy is correlated with decrease in aspartate transaminase. J Transl Int Med., 5(3): $148-154$

19. Koji T, Norihiro F, Eiichi O et al. (2015): Direct-acting antiviral-based triple therapy on alpha-fetoprotein level in chronic hepatitis C patients. World J Gastroenterol., 21(15): 4696-4706

20. Miyaki E, Imamura M, Hiraga N (2016): Daclatasvir and asunaprevir treatment improves liver function parameters and reduces liver fibrosis markers in chronic hepatitis $\mathrm{C}$ patients. Hepatol. Res.,46: 758-764

21. Tachi Y, Hirai T, Ishizu Y (2015): $\alpha$-fetoprotein levels after interferon therapy predict regression of liver fibrosis in patients with sustained virological response. J Gastroen Hepatol., DOI: 10.1111/jgh.13245.

22. Kelvin N, Melissa J, Nima M et al. (2017): Decrease of alpha-fetoprotein in patients with cirrhosis treated with direct-acting antivirals. Journal of clinical and translational hepatology,5(1):43-49.

23. Tatsuo K, Keizo K, Akihito T et al. (2013). Platelet count and sustained virological response in hepatitis $\mathrm{C}$ treatment. World J Hepatol., 5(4): 182-188. 